\title{
RESPONSABILIDADE OBJETIVA NA REPARAÇÃO DO DANO DECORRENTE DE ACIDENTE DE TRABALHO
}

Juliana Carolina Bento

ju_carolb@yahoo.com.br

\section{RESUMO}

Este artigo se pauta na responsabilidade do empregador pelos danos decorrentes de acidente de trabalho, sendo a idéia principal a de que tal responsabilidade deve ser objetiva, em todo e qualquer acidente, típico ou atípico, nos casos em que a atividade normalmente desenvolvida pelo autor do dano implicar, por sua própria natureza, riscos aos direitos de outrem. Tem por finalidade demonstrar que o acidente do trabalho é uma das mais graves violações do direito à saúde do trabalhador, onde, portanto, a teoria do risco encontra primazia para sua aplicação. Palavras-chave: responsabilidade objetiva, acidente do trabalho, teoria do risco.

\begin{abstract}
This article is based on the employer's liability for damages resulting from work accidents, being the main idea the one that such liability should be considered as strict liability in each and every accident, typical or atypical, in cases which the activity normally developed by the perpetrator implies by its own nature, risks to the rights of others. It aims to demonstrate that the work accident is one of the most serious violations of the worker's right to health, in which therefore the risk theory finds primacy for its application.
\end{abstract}

Keywords: strict liability, work accident, risk theory

\section{INTRODUÇÃO}

A responsabilidade civil é a busca do status quo ante, é instrumento de manutenção da harmonia social, na medida em que socorre o que foi lesado, utilizando-se do patrimônio do causador do dano para restauração do equilíbrio rompido. Nela vigora o ideal da justa reparação e do equilíbrio entre o dano e a indenização, daí sua importância.

Com a Constituição Federal de 1988, restou pacificada a controvérsia jurisprudencial e doutrinária sobre o cabimento da responsabilidade civil do empregador pelo acidente de trabalho, quando este incorrer em dolo ou culpa de qualquer grau, diante da norma inserta no artigo $7^{\circ}$, XXVIII, denominada responsabilidade subjetiva.

Entretanto, após a vigência do novo Código Civil de 2002, que estabeleceu, no parágrafo único do artigo 927, a responsabilidade objetiva, ao impor a obrigação de reparar o dano, independentemente de culpa do seu autor, quando a atividade normalmente por este desenvolvida implicar risco aos direitos de outrem, muitas dúvidas e divergências surgiram 
não só na doutrina, mas também na jurisprudência a respeito da aplicação no campo do Direito do Trabalho dessa responsabilidade objetiva, também chamada de teoria do risco, em caso de acidente de trabalho.

Alguns entendem que ela não se aplica, sob o argumento de que a Constituição Federal estabelece como pressuposto da reparação a comprovação de dolo ou culpa do empregador, nos termos do artigo $7^{\circ}$, XXVIII. Em contrapartida, há os que defendem sua aplicação, pois alegam que o caput do próprio artigo $7^{\circ}$ da Constituição estabeleceu apenas um rol mínimo de direitos e garantias aos trabalhadores, sem prejuízo de outros que visam à sua melhor condição social, possibilitando, assim, sua ampliação por legislação infraconstitucional.

Cabe aqui já ressaltar o ensinamento de Cláudio Mascarenhas Brandão nesse sentido:

\begin{abstract}
$\mathrm{O}$ trabalhador possui um direito de proteção à saúde, elevado ao patamar de norma constitucional com natureza jurídica de direito fundamental e que o empregador possui a responsabilidade objetiva pelos danos a ele causados, em virtude de acidentes do trabalho ocorridos no desenvolvimento de atividades de risco acentuado, o que representa a consagração de priorizar o homem como centro da proteção dos sistemas jurídicos ${ }^{1}$.
\end{abstract}

Pode-se afirmar, por conseguinte, que a questão, se analisada sob o prisma social, possui fundamental importância, na medida em que envolve o tema do acidente de trabalho, que se constitui num dos maiores problemas enfrentados atualmente no Brasil. As ocorrências no campo do acidente de trabalho geram consequências traumáticas que acarretam, muitas vezes, a invalidez permanente ou até mesmo a morte, com repercussões danosas para o trabalhador, a sua família, à empresa e à sociedade.

A dimensão do problema e a necessidade premente de soluções não permitem mais ignorá-lo e, portanto, com base nas pesquisas realizadas em doutrinas e jurisprudências, chegou-se à conclusão de que é perfeitamente possível a aplicação da responsabilidade objetiva ou teoria do risco no campo do Direito do Trabalho, quando a atividade normalmente desenvolvida pelo empregador implicar riscos para os direitos de outrem, uma vez que, visa à melhoria da condição social do trabalhador.

\title{
CONSIDERAÇÕES SOBRE ACIDENTE DO TRABALHO
}

O conceito legal de acidente do trabalho está previsto na Lei n. 8.213/91, denominada de Lei dos Planos de Benefícios da Previdência Social, sendo que "a lei definiu apenas o

\footnotetext{
${ }^{1}$ BRANDÃO, Cláudio apud OLIVEIRA, Sebastião Geraldo de. Indenizações por acidente do trabalho ou doença ocupacional. 3. ed. São Paulo: LTr, 2007. p. 128/129.
} 
acidente do trabalho em sentido estrito, o acidente típico, e relacionou outras hipóteses que também geram incapacidade laborativa, os chamados acidentes do trabalho por equiparação."

O artigo 19 da referida Lei, publicada em 24 de julho de 1991, trouxe um conceito mais amplo e atual acerca de acidente de trabalho, abrangendo segurados que até então não se enquadravam na definição anteriormente dada pela Lei n. 6.367/76. De acordo com o citado artigo, "acidente de trabalho é o que ocorre pelo exercício do trabalho a serviço da empresa, ou pelo exercício do trabalho do segurado especial, provocando lesão corporal ou perturbação funcional, de caráter temporário ou permanente".

Portanto, para a configuração do acidente típico, exige-se a lesividade e o nexo de causalidade, sendo necessário que o acidente provoque algum "dano à saúde do trabalhador, gerando uma lesão corporal ou uma perturbação funcional."3 Além disso, importante é salientar que a própria palavra acidente já "imprime ao conceito a marca de causalidade, do acontecimento não desejado nem ocasionado voluntariamente."

É certo que não são apenas os acidentes típicos que são considerados acidente do trabalho. As doenças contraídas pelos empregados em consequência do trabalho são equiparadas a acidente do trabalho. A Lei n. 8.213/91, em seu art. 20, considera como acidente do trabalho a doença ocupacional, tida como espécie que compreende tanto as doenças profissionais quanto as doenças do trabalho.

As doenças profissionais ou tecnopatias são as doenças típicas, peculiares a determinada profissão, causando certas patologias, ou seja, produzidas ou desencadeadas pelo exercício profissional de determinada atividade. Por isso, prescindem de comprovação do nexo de causalidade com o trabalho, uma vez que se presume por lei que decorrem de determinado trabalho. Assim, "a mera comprovação do desempenho da atividade e a existência da doença profissional são suficientes para caracterizar o acidente do trabalho." Como por exemplo, no caso do "empregado de uma mineradora que trabalha exposto ao pó de sílica e contrai silicose." 6

\footnotetext{
${ }^{2}$ OLIVEIRA, Sebastião Geraldo de. Indenização por acidente do trabalho ou doença ocupacional. 3. ed. São Paulo: LTr, 2007. p. 40.

${ }^{3}$ OLIVEIRA, Sebastião Geraldo de. Indenização por acidente do trabalho ou doença ocupacional. 3. ed. São Paulo: LTr, 2008. p. 89.

${ }^{4}$ COIMBRA JUNIOR, Feijó apud OLIVEIRA, Sebastião Geraldo de. Indenização por acidente do trabalho ou doença ocupacional. 3. ed. São Paulo: LTr, 2007. p. 44.

${ }^{5}$ SILVA, Michael Hideo Atakiama. Revista de direito do trabalho 2008 - RDT 131: A responsabilidade civil da empresa por acidente do trabalho. São Paulo: Revista dos Tribunais, 2008. p. 136.

${ }^{6}$ OLIVEIRA, Sebastião Geraldo de. Indenização por acidente do trabalho ou doença ocupacional. 3. ed. São Paulo: LTr, 2008. p. 47.
} 
Quanto às doenças do trabalho ou mesopatias, são "aquelas causadas pela atividade do

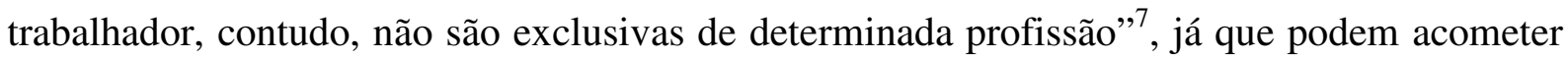
vários segmentos de profissões. José Antônio Ribeiro de Oliveira Silva afirma que "são as desencadeadas em função de condições especiais em que o trabalho é realizado e com ele se relacionam diretamente." ${ }^{\prime 8}$ Portanto, por serem doenças atípicas não possuem nexo presumido, devendo ser comprovado que a patologia sofrida decorre das condições especiais do trabalho desenvolvido.

Por exemplo o grupo das LER/DORT, “já que podem ser adquiridas ou desencadeadas em qualquer atividade, sem vinculação direta a determinada profissão." 9

Por fim, pode ser classificada também como doença ocupacional a proveniente do contágio, infecção ou doença adquirida pelo empregado de forma imprevista, casual, fortuita, durante a execução de suas tarefas, no local de trabalho e durante sua jornada (art. 21, inciso III, da Lei n. 8.213/91). Como acontece se o trabalhador tem ao seu lado um colega portador de doença contagiosa e contamina-se pela proximidade e relação com ele.

A concausalidade prevista no art. 21, inciso I, da Lei n. 8.213/91, é equiparada ao acidente do trabalho se o acidente estiver ligado ao trabalho e, mesmo não sendo a causa única, haja contribuído de forma direta para a morte, redução ou perda da capacidade do segurado ou, ainda, produzido lesão que exija atenção médica para recuperação dele.

"Tal dispositivo reconhece que nem sempre o acidente se apresenta como causa única e exclusiva da lesão ou doença, pois pode haver a conjugação de outros fatores (concausas)."10

Por exemplo, na hemorragia decorrente de um corte profundo, surgido de um acidente do trabalho, não há falar em concausalidade, por ser a hemorragia consequência da própria lesão sofrida; no entanto, se o corte for pequeno e a hemorragia resultar de ser a vítima hemofílica, percebe-se que o grande sangramento não decorreu do corte, e sim da hemofilia, que atuou como causa concorrente ou concausa. $^{11}$

Os incisos II e IV do art. 21 da mencionada Lei tratam dos acidentes por equiparação de mais difícil ocorrência na prática, quais sejam, os sofridos pelo segurado no local e no horário de trabalho, assim como, os sofridos fora do local e do horário de expediente.

\footnotetext{
${ }^{7}$ SILVA, Michael Hideo Atakiama. Revista de direito do trabalho 2008 - RDT 131: A responsabilidade civil da empresa por acidente do trabalho. São Paulo: Revista dos Tribunais, 2008. p. 136.

${ }^{8}$ SILVA, José Antônio Ribeiro de Oliveira. Acidente do trabalho: responsabilidade objetiva do empregador. São Paulo: LTr, 2008. p. 96/97.

${ }^{9}$ OLIVEIRA, Sebastião Geraldo de. Indenização por acidente do trabalho ou doença ocupacional. 3. ed. São Paulo: LTr, 2008. p. 47.

${ }^{10}$ SILVA, José Antônio Ribeiro de Oliveira. Acidente do trabalho: responsabilidade objetiva do empregador. S.ão Paulo: LTr, 2008. p. 101.

${ }^{11}$ SILVA, José Antônio Ribeiro de Oliveira. Acidente do trabalho: responsabilidade objetiva do empregador. São Paulo: LTr, 2008. p. 101/102.
} 
Há que se falar, ainda, dos acidentes por equiparação ocorridos "nos períodos destinados a refeição ou descanso, ou por ocasião da satisfação de outras necessidades fisiológicas, no local do trabalho ou durante este", ${ }^{\text {, }}$, tendo em vista que, conforme o $\S 1^{\circ}$ do art. 21, neste lapso de tempo o empregado é considerado no exercício do trabalho. Neste sentido o Tribunal Regional do Trabalho da $3^{\text {a }}$ Região já decidiu que:

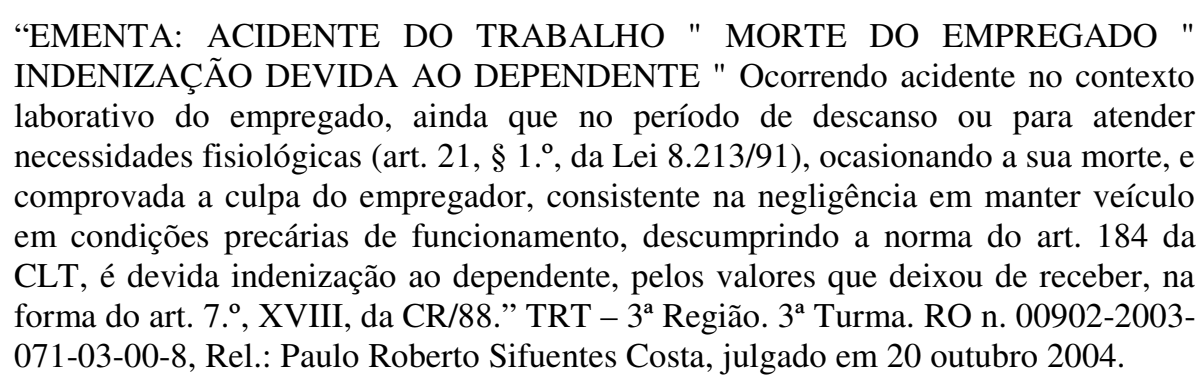

Por fim, o art. 20 da Lei n. 8.213/91, § $1^{\circ}$, exclui expressamente doenças que decorrem do desgaste natural do corpo humano ou da pré-disposição peculiar do indivíduo em desenvolver tal doença.

\title{
EVOLUÇÃO DA RESPONSABILIDADE
}

Necessário é destacar a responsabilidade civil que, no Código Civil, apresenta-se, especialmente, em três dispositivos que se completam, quais sejam:

\begin{abstract}
Art. 186. Aquele que, por ação ou omissão voluntária, negligência ou imprudência, violar direito e causar dano a outrem, ainda que exclusivamente moral, comete ato ilícito.

Art. 187. Também comete ato ilícito o titular de um direito que, ao exercê-lo, excede manifestamente os limites impostos pelo seu fim econômico ou social, pela boa-fé ou pelos bons costumes.

Art. 927. Aquele que, por ato ilícito (arts. 186 e 187), causar dano a outrem, fica obrigado a repará-lo.

Parágrafo único. Haverá obrigação de reparar o dano, independentemente de culpa, nos casos especificados em lei, ou quando a atividade normalmente desenvolvida pelo autor do dano implicar, por sua natureza, risco para os direitos de outrem.
\end{abstract}

No que tange à responsabilidade do empregador pelos danos causados ao empregado em razão do acidente de trabalho, o direito à indenização funda-se no constante anseio social da busca pela justiça, ou seja, tendo o agente causado um dano, deve repará-lo para que reponha a vítima à situação anterior à lesão, de forma in natura ou pecuniária. A regra geral, mas não única, insculpida no art. $7^{\circ}$, XXVIII, da Constituição Federal de 1988, traz a responsabilidade subjetiva que estará sempre subordinada à comprovação do dolo ou culpa do empregador.

\footnotetext{
${ }^{12}$ BRANDÃO, Cláudio apud SILVA, José Antônio Ribeiro de Oliveira. Acidente do trabalho: responsabilidade objetiva do empregador. São Paulo: LTr, 2008. p. 106.
} 
"Dessa forma, o empregador, ao desenvolver sua atividade empresarial, assume os riscos sociais pelo negócio escolhido, sendo a garantia da integridade física e mental de seus empregados uma cláusula implícita no contrato de trabalho (...).",13

O Tribunal Regional do Trabalho da $15^{\text {a }}$ Região já teve oportunidade de decidir que:

\begin{abstract}
"Responsabilidade civil do empregador. Descaracterização. Ausência de culpa do empregador. Não pode o réu ser responsabilizado quando ausente o elemento culpa, uma vez que a autora teve todo o acompanhamento médico, foi submetida à reabilitação, transferida de função, além de participar de programa de orientação contra LER. Recurso a que se nega provimento.” TRT $15^{\text {a }}$ Região - $1^{\text {a }}$ Turma. RO 00111-2006-096-15-00-1, Rel.: Helena Rosa Mônaco S.L. Coelho, julgado em 28 abril 2006.
\end{abstract}

Sendo assim, faz-se imprescindível que o empregado faça "prova de que o empregador agiu ou deixou de agir de forma esperada para garantir a sua segurança ou descumpriu norma legal/regulamentar, evidencie o dano sofrido e, por fim, o nexo de causalidade."14

Apesar dessas considerações, é inegável que o Código Civil de 2002 também veio contemplar a responsabilidade objetiva, com fundamento na teoria do risco criado pelo agente, conforme preceitua o artigo 927, podendo-se dizer que "houve uma evolução salutar no conceito da responsabilidade civil, passando-se de um conceito em que se exigia a existência de culpa para a noção de responsabilidade civil sem culpa, com fundamento no risco."15

Pode-se afirmar, portanto, que:

(...) a moderna doutrina e os novos rumos da responsabilidade civil caminham no sentido da responsabilização objetiva do empregador em razão da teoria da proteção integral da pessoa do trabalhador, da desigualdade entre as partes que compõe a relação de trabalho (tanto econômica como no aspecto processual), da dignidade da pessoa humana do trabalhador, dos valores sociais do trabalho e da justiça social $\left(\operatorname{artigos} 1^{\circ}\right.$, III, IV e $3^{\circ}$, da CF). ${ }^{16}$

O Tribunal Superior do Trabalho já vem decidindo e demonstrando a adoção da mencionada teoria do risco criado no desenvolvimento da atividade da empresa:

“AGRAVO DE INSTRUMENTO. RECURSO DE REVISTA. DANO MORAL.
ACIDENTE DE TRABALHO. RESPONSABILIDADE OBJETIVA (ART. 927,
PARÁGRAFO ÚNICO, CC). INEXISTENCIA DE -CULPA EXCLUSIVA DA
VÍTIMA- (FATO DA VÍTIMA). Demonstrado no agravo de instrumento que o
recurso de revista preenchia os requisitos do art. 896 da CLT, ante a constatação de
violação do art. 927, parágrafo único, do CC. Agravo de instrumento provido.
RECURSO DE REVISTA. DANO MORAL. ACIDENTE DE TRABALHO.
RESPONSABILIDADE OBJETIVA (ART. 927, PARÁGRAFO ÚNICO, CC).

${ }^{13}$ SILVA, Michael Hideo Atakiama. Revista de direito do trabalho 2008 - RDT 131: A responsabilidade civil da empresa por acidente do trabalho. São Paulo: Revista dos Tribunais, 2008. p. 137.

${ }^{14}$ SILVA, Michael Hideo Atakiama. Revista de direito do trabalho 2008 - RDT 131: A responsabilidade civil da empresa por acidente do trabalho. São Paulo: Revista dos Tribunais, 2008. p. 139.

${ }^{15}$ SANTOS, Enoque Ribeiro dos. A responsabilidade subjetiva e objetiva da empresa em face do novo código civil. Disponível em: <http://bdjur.stj.gov.br/jspui/bitstream/2011/18199/2/A_Responsabilidade_Subjetiva_e_Objetiva.pdf>. Acesso em: 13 agosto 2009.

${ }^{16}$ SCHIAVI, Mauro. Aspectos polêmicos do acidente do trabalho: responsabilidade objetiva do empregador pela reparação dos danos causados ao empregado. Disponível em: <www.lacier.com.br/artigos/aspectos_polemicos.doc>. Acesso em: 3 agosto 2009. 
INEXISTÊNCIA DE -CULPA EXCLUSIVA DA VÍTIMA- (FATO DA VÍTIMA). A regra geral do ordenamento jurídico, no tocante à responsabilidade civil do autor do dano, mantém-se com a noção da responsabilidade subjetiva (arts. 186 e 927, caput, CC). Contudo, tratando-se de atividade empresarial, ou de dinâmica laborativa (independentemente da atividade da empresa), fixadoras de risco acentuado para os trabalhadores envolvidos, desponta a exceção ressaltada pelo parágrafo único do art. 927 do CC, tornando objetiva a responsabilidade empresarial por danos acidentários (responsabilidade em face do risco). Noutro norte, a caracterização da culpa exclusiva da vítima é fator de exclusão do elemento do nexo causal para efeito de inexistência de reparação civil no âmbito laboral quando o infortúnio ocorre por causa única decorrente da conduta do trabalhador, sem qualquer ligação com o descumprimento das normas legais, contratuais, convencionais, regulamentares, técnicas ou do dever geral de cautela por parte do empregador. Se, com base nos fatos relatados pelo Regional, se conclui que a conduta da vítima do acidente não se revelou como causa única do infortúnio, afasta-se a hipótese excludente da responsabilização da empregadora pelo dano causado. Recurso conhecido e provido.” TST - 6 $6^{\text {a }}$ Turma. RR 850/2004-021-1240.0, Rel.: Mauricio Godinho Delgado, julgado em 3 junho 2009.

“AGRAVO DE INSTRUMENTO EM RECURSO DE REVISTA. 1. ACIDENTE DO TRABALHO. RESPONSABILIDADE OBJETIVA. ATIVIDADE DE RISCO. $\mathrm{O}$ art. $7^{\circ}, \mathrm{XXVIII}$, da $\mathrm{CF}$, trata das garantias mínimas do trabalhador, de modo que, não há impedimento constitucional que lei infraconstitucional consagre uma maior responsabilidade do empregador nas hipóteses acidentárias (responsabilidade objetiva), posto que restariam mantidos os valores que a Magna Carta buscou conservar, sendo plenamente aplicável, in casu, a -teoria do risco criado-. De outro norte, mesmo na vigência do Código Civil anterior, a responsabilidade objetiva já vinha sendo aplicada, a partir do entendimento jurisprudencial e doutrinário consolidado, calcados no art. $8^{\circ}$ da CLT e nas leis infraconstitucionais de nosso ordenamento jurídico que, regulamentando situações específicas, já traziam em seu bojo esse tipo de responsabilidade. Incólume, assim, o artigo constitucional supracitado, bem como os demais dispositivos invocados. (...)" TST $-8^{\mathrm{a}}$ Turma. AIRR 1034/2005-008-12-40.4, Rel. Dora Maria da Costa, julgado em 23 setembro 2009.

Desse modo, o dano sofrido pela vítima é uma realidade objetiva indiscutível, mas a falta ou a dificuldade de provar o elemento subjetivo da culpa impede o deferimento da indenização, por isso a responsabilidade objetiva já encontra consolidado entendimento jurisprudencial acerca de sua aplicabilidade, sendo evidente a consistência dos argumentos de justiça e equidade para adotá-la quando a atividade desenvolvida pelo empregador for perigosa ou de risco.

Há que se observar, por fim, outro aspecto relevante de que "a cobertura acidentária não exclui, quando cabível, a responsabilidade civil do empregador." ${ }^{\prime 7}$

Essa assertiva foi realmente consagrada e emanou da Constituição Federal, art. $7^{\circ}$, inciso XXVIII, sendo que, em sintonia com esse preceito constitucional, o art. 121 da Lei n. 8.213/91 prevê que: 'o pagamento, pela Previdência Social, das prestações por acidente do trabalho não exclui a responsabilidade civil da empresa ou de outrem.'

\footnotetext{
${ }^{17}$ OLIVEIRA, Sebastião Geraldo de. Indenização por acidente do trabalho ou doença ocupacional. 3. ed. São Paulo: LTr, 2007. p. 73.
} 
Os benefícios da Previdência Social são percebidos pelo empregado acidentado e o pagamento independe da caracterização de culpa, já que a cobertura securitária está pautada na teoria da responsabilidade objetiva.

A par disto, já ficou consignado que:

\begin{abstract}
“ACIDENTE DE TRABALHO. CUMULAÇÃO DA INDENIZAÇÃO DERIVADA DA RESPONSABILIDADE CIVIL COM OS BENEFÍCIOS ACIDENTÁRIOS. A indenização derivada da responsabilidade civil do empregador é devida quando restar caracterizado o dolo ou culpa deste ou de seus prepostos no desenrolar do evento danoso que venha a atingir a vítima, que no caso é o seu empregado. Já a pensão acidentária paga pela Previdência Social resulta da responsabilidade da sociedade em geral pela higidez e segurança do trabalho, como forma de proteção contra os infortúnios aos obreiros e suas famílias, sendo desvinculada de qualquer culpa ou dolo do empregador. Logo, por terem origens distintas, a indenização fundada na responsabilidade civil do empregador e a indenização proveniente da Lei acidentária são parcelas cumuláveis, não havendo que se falar em compensação , nem mesmo em bis in idem. Inteligência do artigo $7^{\circ}$, inciso XXVIII, da CF." TRT 15 Região - RO 00497-2006-142-15-00-8, Rel.: Ana Paula Pellegrina Lockmann, julgado em 6 outubro 2008 .
\end{abstract}

Logo, é de se aferir que o seguro acidentário reserva-se a proteger a vítima e não reduzir ou substituir a obrigação do empregador de reparar o dano causado pelo acidente ocorrido.

\title{
FUNDAMENTOS DA RESPONSABILIDADE OBJETIVA DO EMPREGADOR
}

Alguns doutrinadores entendem que o parágrafo único do art. 927 do Código Civil não se aplica nas hipóteses de acidente do trabalho, visto que "norma alguma de hierarquia inferior poderia contrariar a previsão constitucional." 18

Neste sentido, Helder Dal Col também registra que:

Querer responsabilizar objetivamente o empregador por qualquer acidente sofrido pelo empregado é fadar a relação de trabalho ao insucesso, tornando-a inviável. A ele cabe a responsabilidade pela falha na prevenção, pelo excesso de jornada imposto, pela inobservância das regras de ergonomia, segurança e outras, que comprometam a normalidade do ambiente do trabalho ou das condições em que este devia ter-se realizado, ou seja, quando cria condições inseguras para o trabalhador. O sistema da culpabilidade subjetiva é, ainda, o mais coerente para fins de reparação de danos, sobretudo quando estabelecido no país um sistema de previdência social, que repara objetivamente $\mathrm{o}$ acidente, funcionando como seguro contra a infortunística. E se pudesse ser tido como atividade culposa do empregador, permitir o trabalho em atividades que são perigosas por sua própria natureza, haveria séria justificativa para desestimular a produção, agravando o desemprego, que já assola a sociedade com índices crescentes e alarmantes. ${ }^{19}$

\footnotetext{
${ }^{18}$ OLIVEIRA, Sebastião Geraldo de. Indenização por acidente do trabalho ou doença ocupacional. 3. ed. São Paulo: LTr, 2007. p. 107.

${ }^{19}$ DAL COL, Helder Martinez apud OLIVEIRA, Sebastião Geraldo de. Indenização por acidente do trabalho ou doença ocupacional. 3. ed. São Paulo: LTr, 2007. p. 107/108.
} 
Outros justificam que, ao se impor a excessiva atenção à vítima juntamente com o dever de reparar, acaba-se por negar o princípio da justiça social, levando a equiparar o comportamento jurídico e antijurídico do agente. ${ }^{20}$ Alegam, ainda, que se o pretexto da culpa for afastado, aquele que age de maneira apropriada, tomando todas as medidas estimadas para evitar os danos, receberia o mesmo tratamento do outro que atua displicentemente. ${ }^{21}$

Entretanto, vale salientar que:

A previsão constitucional sobre responsabilidade subjetiva não tem o condão, por si só, de excluir a objetiva; ao contrário, ambas podem e devem conviver harmoniosamente, em especial porque a culpa é insuficiente para solução de determinados casos concretos, porquanto, amiúde, deixa sem reparação danos sofridos por pessoas que não conseguem provar a falta do agente; sem dúvida, não é essa a finalidade do Direito. ${ }^{22}$

A Constituição da República estabelece em seu artigo $7^{\circ}$ apenas um rol exemplificativo de garantias sociais do trabalhador.

Nesta direção, já ficou registrado na jurisprudência que:

"RECURSO DE REVISTA. DANO MORAL. ARTIGO $7^{\circ}$, XXVIII, DA CONSTITUIÇÃO FEDERAL. CULPA LATO SENSU. PRECEDENTE DA SBDI-1 DESTA CORTE. DESPROVIMENTO. A interpretação sistemática e teleológica do art. $7^{\circ}$, caput e XXVIII, da Constituição Federal, permite concluir que o rol de direitos dos trabalhadores ali enumerados não é taxativo, em nada impedindo que sejam atribuídos outros direitos aos trabalhadores, bastando que impliquem a melhoria de sua condição social. Assim, o inciso XXVIII do artigo $7^{\circ}$ da Carta Magna traz um direito mínimo do trabalhador à indenização por acidente de trabalho, no caso de dolo ou culpa, mas outra norma pode atribuir uma posição mais favorável ao empregado que permita a responsabilidade por culpa lato sensu. Assim, a teoria do risco profissional considera que o dever de indenizar decorre da própria atividade profissional, principalmente naquelas de risco acentuado ou excepcional pela natureza perigosa, de modo que a responsabilidade incide automaticamente. Assim, a obrigação de indenizar por ocorrência de acidente de trabalho subsiste, incidindo na hipótese a regra do parágrafo único do artigo 927 do Código Civil, no que se refere à ocorrência da responsabilidade sem culpa stricto sensu. Recurso de revista conhecido, por divergência jurisprudencial, e desprovido. VALOR DA INDENIZAÇÃO. PRINCÍPIOS DA PROPORCIONALIDADE E DA RAZOABILIDADE. $\mathrm{O}$ art. $5^{\circ}, \mathrm{V}$, da Constituição Federal, trata da indenização por dano moral ou à imagem decorrente do direito de resposta, não se enquadrando, portanto, na hipótese de indenização por acidente de trabalho, não se verificando, sob tal aspecto, afronta direta e literal (art. 896, -c-, da CLT) do mencionado dispositivo constitucional. Os arestos apresentados são oriundos de Turmas desta Corte, inservíveis, a teor da alínea -a- do art. 896 da CLT. Recurso de revista não conhecido." TST $-6^{\text {a }}$ Turma. RR 2289/2005-482-01-00.2, Rel.: Aloysio Corrêa da Veiga, julgado em 2 outubro 2009.

\footnotetext{
${ }^{20}$ PEREIRA, Caio Mário da Silva. Responsabilidade civil. 9. ed. Rio de Janeiro: Forense, 2002. p. 271.

${ }^{21}$ OLIVEIRA, Sebastião Geraldo de. Indenização por acidente do trabalho ou doença ocupacional. 3. ed. São Paulo: LTr, 2007. p. 98.

${ }^{22}$ GONÇALVES, Marcos Fernandes. As teorias da culpa e do risco nos acidentes do trabalho. Juslaboral.net. Disponível em: <http://www.juslaboral.net/2009/01/as-teorias-da-culpa-e-do-risco-nos.html>. Acesso em: 23 agosto 2009.
} 
A norma genérica encampando a teoria do risco, no parágrafo único do art. 927 Código Civil passou a conviver no mesmo patamar de importância e generalidade da teoria da responsabilidade subjetiva.

Imprescindível é observar ainda que a definição legal da chamada "atividade de risco", inserta na segunda parte do polêmico parágrafo único do art. 927, do novo Código Civil, restou ignorada, cedendo para a jurisprudência esta conceituação no caso concreto:

"INDENIZAÇÃO POR DANOS MORAIS E MATERIAIS - INEXISTÊNCIA DE
CULPA OU DOLO DA RECLAMADA - RESPONSABILIDADE OBJ E TIVA -
IMPOSSIBILIDADE. 1. Tendo o Regional confirmado a sentença condenatória que determinou o pagamento de indenização por danos morais e materiais decorrentes de acidente de trabalho, sob o fundamento de que, independentemente de culpa da Reclamada, a sua responsabilização seria objetiva, de se acolher o pleito recursal. 2. Isso porque a responsabilidade objetiva fundada no risco da atividade, configura-se, em tese, apenas quando a atividade desenvolvida pelo autor do dano vier a causar ao trabalhador um ônus maior do que os demais membros da coletividade. 3. Como o Empregado, no caso, foi vitimado por um acidente automobilístico quando retornava de sua atividade, não há de se falar em situação de risco superior a qualquer outro cidadão. Logo, para que pudesse haver a responsabilização do empregador pelo dano, haveria a necessidade de inequívoca prova de culpa, o que inocorreu. Recurso de revista provido." TST - $7^{\mathrm{a}}$ Turma. RR 555/2005-012-17-00, Rel.: MARIA DORALICE NOVAES, julgado em 16 setembro 2009.

“A Portaria n. ${ }^{\circ}$ 3.393/1987 do Ministério do Trabalho e Emprego, vigente à época da contratação, estabeleceu como atividade de risco em potencial aquelas relativas à operação com aparelhos de raios-X, tendo sido editada em face da autorização contida no artigo 200, cabeça e inciso VI, da Consolidação das Leis do Trabalho. Referido dispositivo atribui ao Ministério do Trabalho e Emprego a competência para o estabelecimento de disposições complementares às normas de Segurança e Medicina do Trabalho, abrangendo, portanto, aquelas relativas às atividades perigosas. Tal delegação de competência evidencia-se claramente no parágrafo único do citado preceito consolidado, onde resta consignado que: -tratando-se de radiações ionizantes e explosivos, as normas a que se refere este artigo serão expedidas de acordo com as resoluções a respeito adotadas pelo órgão técnico-.

Conclui-se, pois, da exegese do dispositivo em comento, não ser taxativo o rol de atividades ou operações perigosas declinado no artigo 193 da CLT, principalmente quando considerado que a norma legal, ao conceituar as atividades ou operações perigosas, remete à observância da regulamentação aprovada pelo Ministério do Trabalho e Emprego." TST - 1 a Turma. RR 72846/2003-900-02-00.5, Rel.: Lelio Bentes Corrêa, julgado em 16 setembro 2009.

De acordo com Sebastião Geraldo de Oliveira, o risco que acarreta o direito à reparação:

(...) deverá ser analisado casuisticamente, considerando a natureza da atividade do empregador, ou seja, o seu grau específico de risco. (...)

Se o risco a que se expõe o trabalhador estiver acima do risco médio da coletividade em geral, caberá o deferimento da indenização, tão-somente pelo exercício dessa atividade. $^{23}$

Amauri Mascaro Nascimento assevera que, no Direito do Trabalho, o objetivo maior é social, qual seja, a promoção da melhoria das condições sociais do trabalhador. Daí por que a

\footnotetext{
${ }^{23}$ OLIVEIRA, Sebastião Geraldo de. Indenização por acidente do trabalho ou doença ocupacional. 3. ed. São Paulo: LTr, 2007. p. 112/113.
} 
própria União, que tem competência para legislar sobre Direito do Trabalho, permite, salvo exceções, "que normas e condições de trabalho mais vantajosas para os assalariados, conferindo direitos acima dos que previu na Constituição, venham a ser criadas pelas normas inferiores do escalonamento". Esse aspecto influiu na formação de um princípio próprio do direito do trabalho no que tange à hierarquia de suas normas: o princípio da norma mais favorável ao trabalhador.

Por tal razão, o Direito do Trabalho não acolhe o sistema clássico, mas, sim, o princípio da hierarquia dinâmica das normas, consistente na aplicação prioritária de uma norma fundamental que sempre será a mais favorável ao trabalhador, salvo disposições estatais imperativas ou de ordem pública. ${ }^{24}$

Ressalte-se, finalmente, que:

A postulação judicial das indenizações por danos materiais, morais e/ou estéticos, por parte daquele empregado que foi vítima de acidente ou doença ocupacional, exige, previamente, que o evento danoso esteja enquadrado nas hipóteses que a Lei n. 8.213/91 considera como acidente do trabalho. ${ }^{25}$

Vale dizer que, situações que, por equiparação legal (artigos 20 e 21 da Lei 8.213/91), se consideram acidentes de trabalho, se enquadrados na situação prevista pelo artigo 927, parágrafo único do $\mathrm{CC}$, também quanto a elas poderá incidir a responsabilidade objetiva.

\section{A RESPONSABILIDADE PREVISTA NO PARÁGRAFO ÚNICO DO ARTIGO 927 DO CÓDIGO CIVIL}

A teoria da responsabilidade civil encontrou seu mais digno desenvolvimento no campo da chamada infortunística, que estuda a responsabilidade derivada de acidente do trabalho, em sua concepção ampla, cingindo o acidente típico e as doenças ocupacionais.

O Novo Código Civil traz em seu artigo 927, parágrafo único, o que é considerado pela doutrina uma das grandes inovações, talvez a maior, em matéria obrigacional.

Para Caio Mário da Silva Pereira, a teoria do risco criado é a que melhor se adapta às condições de vida social. Sintetiza o autor:

(...) aquele que, em razão de sua atividade ou profissão, cria um perigo, está sujeito à reparação do dano que causar, salvo prova de haver adotado todas as medidas idôneas a evitá-lo. (...) A teoria do risco criado importa em ampliação do conceito do risco proveito. Aumenta os encargos do agente, é, porém, mais eqüitativa para a

\footnotetext{
${ }^{24}$ NASCIMENTO, Amauri Mascaro. Iniciação ao direito do trabalho. 31. ed. São Paulo: LTr, 2005. p. 118.

${ }^{25}$ OLIVEIRA, Sebastião Geraldo de. Indenização por acidente do trabalho ou doença ocupacional. 3. ed. São Paulo: LTr, 2007. p. 38.
} 
vítima, que não tem de provar que o dano resultou de uma vantagem ou de um benefício obtido pelo causador do dano. ${ }^{26}$

Logo, é importante destacar que "o trabalhador e o empregador, quando se ligam pelo contrato de trabalho, contraem obrigações especialíssimas, dentre as quais de suma importância a da segurança material, que o segundo deve proporcionar ao primeiro" ${ }^{27}$, assim sendo "a responsabilidade contratual objetiva deve ser aplicada para a proteção da saúde do trabalhador, diante da imensa dificuldade de produção da prova da culpa do empregador, na ocorrência de acidente do trabalho e doença ocupacional." 28

É certo que a saúde é classificada como um direito humano ou fundamental inviolável e sua importância se acentuou ainda mais após a Emenda Constitucional n. 45/2004, devendo ser observada demasiadamente tanto pelo empregador quanto pelo Estado. Esse direito, cotidianamente, sofre inúmeras agressões e, por isso, na busca de respostas adequadas para guiar o intérprete nos casos concretos que dizem respeito à mais grave delas, o acidente do trabalho, o Tribunal Superior do Trabalho, na primeira Jornada de Direito Material e Processual da Justiça do Trabalho, aprovou os Enunciados n. 37, 38 e 40, que recomendam, respectivamente a responsabilidade civil objetiva em três hipóteses:

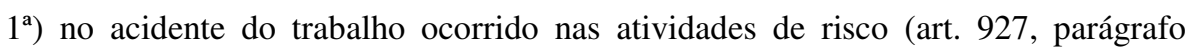
único, do CC/2002); $2^{\mathrm{a}}$ ) nas doenças ocupacionais decorrentes de danos ao meio ambiente do trabalho (art. 225, $\S 3^{\circ}$, da Constituição Federal); $3^{a}$ ) no acidente do trabalho envolvendo empregados de pessoas jurídicas de Direito Público interno (art. 37, § $6^{\circ}$, da CF/88)..$^{29}$

Importante salientar, por fim, que o empregador, por ser quem aufere todos os lucros da atividade empresarial, deve responder, independentemente de culpa de sua parte, pelos danos derivados de acidente do trabalho. No entender de Maurício Godinho Delgado, “em suma, o empregador assume os riscos da empresa, do estabelecimento e do próprio contrato de trabalho e sua execução." ${ }^{, 30} \mathrm{O}$ fundamento dessa afirmativa é o art. $2^{\circ}$ da CLT que prevê a teoria do risco em toda a sua natureza de ser e, além disso, que a responsabilidade do

\footnotetext{
${ }^{26}$ PEREIRA, Caio Mário da Silva. Responsabilidade civil. 9. ed. Rio de Janeiro: Forense, 2002. p. 24.

27 MORAES, Evaristo de apud SILVA, José Antônio Ribeiro de Oliveira. Acidente do trabalho: responsabilidade objetiva do empregador. São Paulo: LTr, 2008. p. 161.

${ }^{28}$ SILVA, José Antônio Ribeiro de Oliveira. Acidente do trabalho: responsabilidade objetiva do empregador. São Paulo: LTr, 2008. p. 183.

29 SILVA, José Antônio Ribeiro de Oliveira. A responsabilidade objetiva do empregador pelos danos decorrentes de acidente do trabalho. CAMAT. Disponível em: $<$ HTTP://WWW.CAMAT.COM.BR/CAMAT/INDEX.PHP?OPTION=COM_CONTENT\&VIEW=ARTICLE\&ID=50\&ITEMID=60 >. Acesso em: 13 setembro 2009.

${ }^{30}$ DELGADO, Mauricio Godinho. Curso de direito do trabalho. 8. ed. São Paulo: LTr, 2009. p. 374.
} 
empregador pelos danos decorrentes de acidente do trabalho "é de natureza trabalhista e inerente ao próprio contrato de trabalho."31

Faz-se necessário destacar, por fim, os princípios do Direito do Trabalho que devem ser compreendidos como elementos de fundamental importância na elaboração e aplicação da norma jurídica no âmbito deste ramo do Direito. Ressalte-se que "as decisões devem assentarse nos princípios jurídicos, e não apenas na letra supostamente suficiente do legislador."32

Assim, dentre os princípios enumerados em Direito do Trabalho, vale destacar o princípio da proteção que sugere um auxílio preferencial a uma das partes, qual seja, o trabalhador, com a finalidade primordial de "alcançar uma igualdade substancial e verdadeira" ${ }^{\prime 3}$ entre elas no âmbito do Direito do Trabalho.

Sendo assim, a referida igualdade substancial tem por escopo equiparar as partes desiguais, quais sejam, empregado e empregador.

Quanto às excludentes de responsabilidade, são aquelas que interferem na possibilidade de indenização de um dano sofrido por alguém, tornando impossível “(...) o acolhimento da responsabilidade civil patronal por ausência do pressuposto do nexo causal ou do nexo de imputação do fato ao empregador."34

São consideradas excludentes da responsabilidade civil decorrente de acidente de trabalho os acidentes causados por culpa exclusiva da vítima, caso fortuito, força maior ou fato de terceiro. Tais fatores impedem o dever de indenizar, uma vez que não há prova de que o empregador ou a prestação do serviço tenham sido os causadores do infortúnio.

\section{CONCLUSÃO}

A regra geral é que a responsabilidade do empregador por qualquer dano causado ao seu empregado seja perquirida de maneira subjetiva, sendo que este preceito se encontra previsto no art. $7^{\circ}$, XXVIII da Constituição Federal. Entretanto, a ameaça constante à saúde e à integridade física e psíquica do trabalhador, a multiplicidade de acidentes e de doenças do trabalho, bem como a dificuldade comprobatória de grande parte dos sinistros e da culpa do autor do dano, fizeram surgir a teoria do risco ou da responsabilidade objetiva, segundo a

\footnotetext{
31 SILVA, José Antônio Ribeiro de Oliveira. A responsabilidade objetiva do empregador pelos danos decorrentes de acidente do trabalho. CAMAT. Disponível em: $<$ HTTP://WWW.CAMAT.COM.BR/CAMAT/INDEX.PHP?OPTION=COM_CONTENT\&VIEW=ARTICLE\&ID=50\&ITEMID=60 $>$. Acesso em: 13 setembro 2009.

${ }^{32}$ BARROS, Alice Monteiro de. Curso de direito do trabalho. São Paulo: LTr, 2005. p.168.

33 PLÁ RODRIGUES, Américo. Princípios de direito do trabalho. 3. ed. São Paulo: LTr, 2000. p. 83.

${ }^{34}$ OLIVEIRA, Sebastião Geraldo de. Indenização por acidente do trabalho ou doença ocupacional. 3. ed. São Paulo: LTr, 2007. p. 146.
} 
qual, haverá sempre a obrigação do empregador de indenizar, independentemente de dolo ou culpa, bastando a comprovação do nexo causal entre o ato lesivo e o dano ou prejuízo ocorrido.

O Código Civil de 2002 incorporou essa teoria através do art. 927, parágrafo único, pelo qual o dever de reparar o dano surge da atividade normalmente exercida pelo agente que cria risco em potencial a direitos ou interesses alheios. Logo, é imprescindível que a atividade implique riscos, perigos, devendo-se entender que, se a atividade, pela sua própria natureza, não implicar riscos para os direitos de outrem, permanecerá a responsabilização subjetiva, ou seja, será indispensável a comprovação de dolo ou culpa do autor do ato danoso.

Nesse ponto é importante destacar que não mais o autor do ato ilícito, mas sim a vítima do dano será o enfoque central da responsabilidade civil. Em outros termos, a responsabilidade que antes era centrada no sujeito responsável, volta-se agora para a vítima e a reparação do dano por ela sofrido.

Vale salientar que o disposto no caput do citado artigo constitucional não é obstáculo a esse entendimento, já que estabelece apenas um rol de direitos mínimos aos trabalhadores urbanos e rurais, sem impedir que outros surjam para melhoria dos ali já consagrados.

Além disso, com amparo no art. $2^{\circ}$ da Consolidação das Leis do Trabalho, é incontestável que a responsabilidade objetiva é de natureza trabalhista e ligada ao próprio contrato de trabalho, visto que estabelece que o empregador, por auferir os lucros, assume todos os riscos da atividade econômica.

Por fim, é preciso frisar que seria um contrassenso admitir que determinada empresa ou empresário, que exerce atividade de risco, fosse obrigado a indenizar um terceiro pela aplicação da teoria do risco, mas não seus empregados, por mera interpretação restritiva do artigo $7^{\circ}$ da Constituição Federal. Haveria aí um autêntico retrocesso histórico, na medida em que o Direito do Trabalho sempre buscou uma tutela mais protetiva aos empregados, inclusive tendo como um de seus pilares o princípio da proteção ao empregado, visando a um equilíbrio nas relações de trabalho. Em tal hipótese, as relações civis estariam albergadas por maior proteção legal.

Em linhas gerais, conclui-se que a importância deste estudo reside no fato de o acidente do trabalho, tanto típico como por equiparação, constituir uma das mais sérias ameaças do direito à saúde do trabalhador e, nessa linha de raciocínio, considerados os princípios de Direito do Trabalho, pode-se afirmar que, no âmbito desse ramo do Direito, é perfeitamente aplicável a teoria do risco quando a atividade normalmente desenvolvida 
implicar risco aos direitos de outrem, na hipótese prevista no parágrafo único do art. 927 do Código Civil.

\section{REFERÊNCIAS BIBLIOGRÁFICAS}

BARROS, Alice Monteiro de. Curso de direito do trabalho. São Paulo: LTr, 2005.

DELGADO, Mauricio Godinho. Curso de direito do trabalho. 8. ed. São Paulo: Ltr, 2009.

GONÇALVES, Marcos Fernandes. As teorias da culpa e do risco nos acidentes do trabalho. Juslaboral.net. Disponível em: <http://www.juslaboral.net/2009/01/as-teorias-da-culpa-e-dorisco-nos.html>. Acesso em: 23 agosto 2009.

NASCIMENTO, Amauri Mascaro. Iniciação ao direito do trabalho. 31. ed. São Paulo: LTr, 2005.

OLIVEIRA, Sebastião Geraldo de. Indenização por acidente do trabalho ou doença ocupacional. 3. ed. São Paulo: LTr, 2007.

PEREIRA, Caio Mário da Silva. Responsabilidade civil. 9. ed. Rio de Janeiro: Forense, 2002.

PLÁ RODRIGUES, Américo. Princípios de direito do trabalho. 3. Ed. São Paulo: LTr, 2000.

SANTOS, Enoque Ribeiro dos. A responsabilidade subjetiva e objetiva da empresa em face do novo código civil. Disponível em: <http://bdjur.stj.gov.br/jspui/bitstream/2011/18199/2/A_Responsabilidade_Subjetiva_e_Objet iva.pdf>. Acesso em: 13 agosto 2009.

SCHIAVI, Mauro. Aspectos polêmicos do acidente do trabalho: responsabilidade objetiva do empregador pela reparação dos danos causados ao empregado. Disponível em: <www.lacier.com.br/artigos/aspectos_polemicos.doc>. Acesso em: 3 agosto 2009.

SILVA, José Antônio Ribeiro de Oliveira. Acidente do trabalho: responsabilidade objetiva do empregador. São Paulo: LTr, 2008.

SILVA, José Antônio Ribeiro de Oliveira. A responsabilidade objetiva do empregador pelos danos decorrentes de acidente do trabalho. CAMAT. Disponível em: <HTTP://WWW.CAMAT.COM.BR/CAMAT/INDEX.PHP?OPTION=COM_CONTENT\&VIEW=ARTICLE\&I $\mathrm{D}=50 \& \mathrm{ITEMID}=60>$. Acesso em: 13 setembro 2009.

SILVA, Michael Hideo Atakiama. Revista de direito do trabalho 2008 - RDT 131: A responsabilidade civil da empresa por acidente do trabalho. São Paulo: Revista dos Tribunais, 2008. 